\title{
Pulmonary oedema during treatment of acute water intoxication
}

\author{
D. MAClean \\ M.B., Ch.B., Ph.D., M.R.C.P. \\ D. B. TRASH \\ M.B., B.S., M.R.C.P.
}

M. Champion

B.Sc., M.B., Ch.B.

University Department of Medicine and the Medical Professorial Unit, Ninewells Hospital and Medical School, Dundee

\begin{abstract}
Summary
Acute water intoxication with deepening coma and uncontrolled epileptiform seizures in a 25-year-old previously fit male schizophrenic was treated with hypertonic (2 N) saline and a $20 \%$ mannitol solution. This improved his neurological state but precipitated severe pulmonary oedema. Intravenous frusemide increased his urinary output sufficiently to clear the pulmonary oedema. In acute water intoxication the use of hypertonic solutions may thus precipitate left heart failure by expanding the intra-pulmonary blood volume beyond the capacity of even a healthy left ventricle to compensate. Simple water restriction will produce a slower but perhaps safer improvement.
\end{abstract}

\section{Introduction}

The syndrome of acute water intoxication is characterized by dilution and therefore hypotonicity of the plasma. It may arise whenever the intake of water exceeds the capacity of the kidneys to excrete it and, when the intake of water is excessive, as in psychogenic polydipsia, it may occur despite normal renal function. The clinical manifestations of the syndrome are largely determined by the fall in plasma osmolality, particularly when this occurs rapidly. The excess water is fairly evenly distributed throughout the total body water so that cerebral oedema becomes responsible for the development of coma and epileptiform seizures.

Treatment normally consists simply of restricting further water intake, but small volumes of hypertonic saline have been used successfully to raise the osmolality of the plasma and thereby speed the resolution of cerebral oedema and shorten the duration of the coma (Alexander, Crow and Hamilton, 1973). A case is reported of acute water intoxication

Correspondence: Dr D. Maclean, 159 Clark Street, Newton Centre, Massachusetts 02159, U.S.A. (in U.S.A. for two years only). Dr D. Maclean, University Department of Medicine, Ninewells Hospital and Medical School, Dundee DD1 9SY, in a young patient with previously normal cardiovascular and renal function in which this form of therapy unexpectedly produced severe pulmonary oedema.

\section{Case summary}

The patient, a 25-year-old male schizophrenic had been drinking large amounts of water for several hours before and rapid onset of vomiting, epileptiform seizures and coma.

He was comatose on admission but exhibited a 8 minimal response to painful stimuli. His tendon reflexes were brisk, there was bilateral sustainedk ankle clonus and the pupils were widely dilated. The onset of status epilepticus necessitated treatment with intravenous chlormethiazole edisylate (Heminevrin) and oxygen, but $150 \mathrm{ml}$ of a $20 \%$ solution of mannitol were also given intravenously in an effort to produce maximum water diuresis.

His initial chest X-ray (Fig. 1a) showed bilateral patchy opacification of the lung fields, but especially marked on the right side. Inhalation of vomitus was suspected and, following endotracheal intubation, bronchial suction and aspiration of his stomach, he was given ampicillin and high doses of hydrocortisone. Hypertonic $(2 \mathrm{~N})$ saline was then given under the control of central venous pressure (CVP) monitoring in an attempt to raise the plasma osmolality and speed the removal of the excess intracellular water in the brain (Fig. 2). A further $200 \mathrm{ml}$ of $20 \%$ mannitol solution were also given.

Despite the maintenance of a high urinary water output and consistently normal CVP readings, he continued to deteriorate and failed to respond to any stimuli. Hyperpnoea, tachycardia $(180 / \mathrm{min})$, hypertension $(210 / 120 \mathrm{mmHg})$ and pyrexia $\left(39.5^{\circ} \mathrm{C}\right)$ developed together with striking generalized capillary dilatation. His condition then gradually stabilized before slowly starting to improve. The infusion of hypertonic saline was therefore discontinued (Fig. 2). 

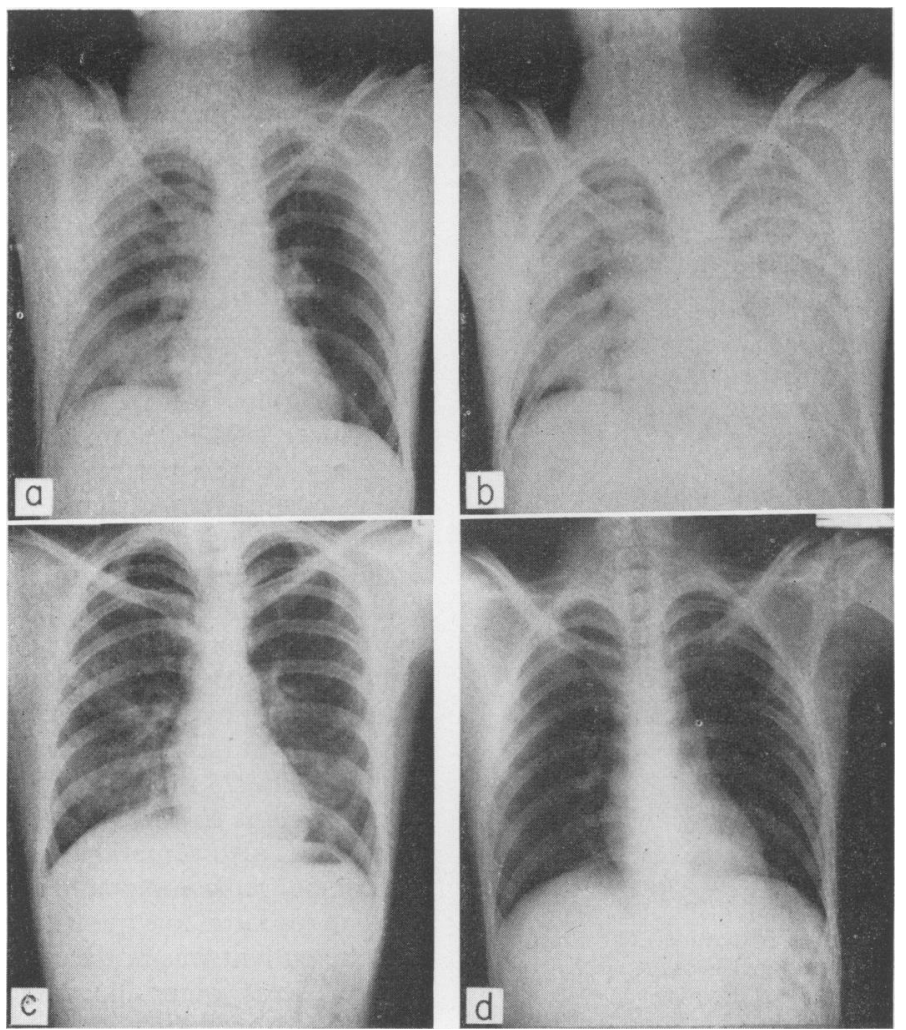

FIG. 1. Serial chest $\mathrm{X}$-rays. (a) On admission, showing patchy opacification in both lung fields, but especially on the right side. (b) At the completion of the $2 \mathrm{~N}$ saline infusion, showing widespread, bilateral pulmonary oedema. (c) Three hours after $80 \mathrm{mg}$ of frusemide i.v., showing substantial clearing of the pulmonary oedema. (d) Day three, normal.

TABLE 1. Serum electrolyte, urea and osmolality values

\begin{tabular}{|c|c|c|c|c|c|c|}
\hline & \multirow{2}{*}{$\begin{array}{c}6 \text { Weeks } \\
\text { before } \\
\text { episode }\end{array}$} & \multicolumn{2}{|c|}{$2 \mathrm{~N}$ Saline therapy } & \multirow{2}{*}{$\begin{array}{c}4 \mathrm{hr} \\
\text { after } \\
\text { frusemide }\end{array}$} & \multirow{2}{*}{$\begin{array}{c}\text { Day } \\
3\end{array}$} & \multirow{2}{*}{$\begin{array}{c}\text { Day } \\
7\end{array}$} \\
\hline & & Before & On completion & & & \\
\hline $\mathrm{Na}(\mathrm{mEq} / 1)$ & 138 & 112 & 126 & 128 & 132 & 135 \\
\hline $\mathrm{K}(\mathrm{mEq} / 1)$ & $3 \cdot 8$ & $3 \cdot 8$ & $4 \cdot 4$ & $4 \cdot 0$ & $3 \cdot 8$ & $4 \cdot 1$ \\
\hline $\mathrm{Cl}(\mathrm{mEq} / 1)$ & 100 & 76 & 95 & 98 & 94 & 99 \\
\hline $\mathrm{CO}_{2}(\mathrm{mEq} / 1)$ & 28 & 23 & 21 & 26 & 27 & 29 \\
\hline Urea $(\mathrm{mg} / 100 \mathrm{ml})$ & 24 & 10 & 16 & 30 & 46 & 32 \\
\hline O`molality $\left(\mathrm{mmol} / \mathrm{kg} \mathrm{H}_{2} \mathrm{O}\right)$ & - & - & 270 & 273 & - & 284 \\
\hline
\end{tabular}

A repeat chest X-ray at this stage showed changes consistent with severe pulmonary oedema (Fig. 1b) and arterial blood-gas and acid-base studies $(\mathrm{pH}$ $7 \cdot 43, \mathrm{PCO}_{2} 22 \mathrm{mmHg}, \mathrm{PO}_{2} 37 \mathrm{mmHg}, \mathrm{HCO}_{3} 21$ $\mathrm{mEq} / 1$, base deficit $7 \mathrm{mEq} / 1$ ) supported this diagnosis. The pulmonary oedema and the urine output did not change appreciably in response to a further $200 \mathrm{ml}$ of $20 \%$ mannitol solution but the pulmonary oedema did clear substantially after $80 \mathrm{mg}$ of fruse- mide were given intravenously (Figs. 1c, 2). Within $36 \mathrm{hr}$ of his admission his chest X-ray was again clear (Fig. 1d).

Full consciousness was restored within $48 \mathrm{hr}$ of starting the therapy, but although he responded well to verbal commands he remained disorientated for a time. His subsequent hospital course was uneventful and follow-up serum electrolyte values were consistently normal (Table 1). 

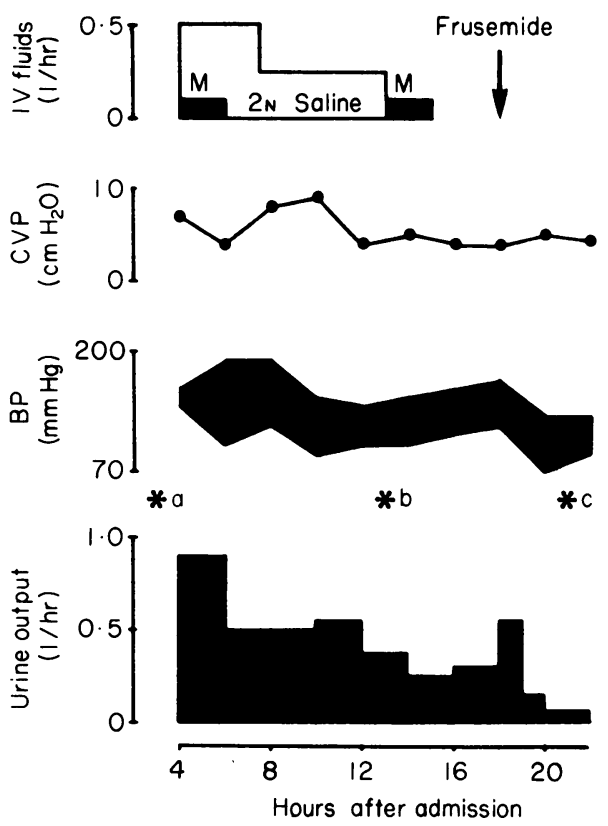

FIG. 2. Chart showing the responses of the central venous pressure, systemic blood pressure and urinary output to the i.v. infusions of $20 \%$ mannitol solution (M) and $2 \mathrm{~N}$ saline and to the injection of frusemide. The timing of three of the X-rays shown in Fig. 1 is indicated by the asterisks.

\section{Comment}

The diagnosis of acute water intoxication rested on the history and the low serum sodium and osmolality. The patient had not taken any drug capable of causing an inappropriate antidiuresis nor did he have any medical disorder such as thyroid deficiency or acute porphyria recognized as sometimes being associated with mental illness or an inappropriate antidiuresis. His serum electrolytes had been measured routinely at the time of his admission to a mental hospital 6 weeks before his acute illness and were then normal (Table 1); moreover, his hyponatraemia was only of intermediate severity (serum $\mathrm{Na} 112 \mathrm{mEq} / 1$ ) so it is unlikely that he had preexisting symptomless hyponatraemia. He seems, like others, simply to have drunk himself into a state of acute water intoxication (Bewley, 1964; Alexander et al., 1973) by drinking the water at a rate in excess of the maximum rate of water diuresis, i.e. between 12 and $20 \mathrm{ml} / \mathrm{min}$.

The speed of onset, rather than the actual severity of the hyponatraemia determines the clinical picture, but treatment should depend on the patient's neurological state. The management was fairly standard, although a more hypertonic, e.g. $5 \mathrm{~N}$, form of saline could have been used (Alexander et al., 1973). The hypertonic $(20 \%)$ solution was given to promote maximum water diuresis as well as to enhance the transfer of intracellular water to the plasma. The treatment produced rapid improvement in the patient's level of consciousness, whereas water restriction alone might have prolonged his coma for several days.

In acute water intoxication the extracellular fluid volume is not reduced, nor is there more than a very minor degree of sodium loss (Leaf et al., 1953) so the danger of giving hypertonic saline solutions is that as they exert their osmotic effects and return the over-expanded intracellular space towards normal (Rowntree, 1922; Wynn and Rob, 1954) they will over-expand the plasma volume too rapidly and produce pulmonary oedema. Such an acute challenge, however, normally has no adverse effects as the bulk of the excess water is excreted within about twentyfour hours. There do not appear to be any previous reports of severe pulmonary oedema being precipitated during the treatment of acute water intoxication with hypertonic saline. Conceivably, the patient might have had a cardiotoxic effect from the amitriptyline $25 \mathrm{mg}$ t.d.s. which he had been taking regularly, but this seems a remote possibility. Propranolol is also sometimes used in the management of schizophrenia and would interfere with the normal cardiac response to expansion of the plasma volume, but the patient was not receiving this drug.

The excess water in acute water intoxication is distributed over the total body water such that the ratio of intracellular to extracellular water remains unchanged (Leaf et al., 1954; Wynn and Houghton, 1957). This information can be used to calculate the amount of hypertonic saline required to correct any given drop in the osmolality of the plasma but it is usually sufficient only partially to correct the hypoosmolality and to leave the patient to make the final fine adjustments himself. It is worth emphasizing that clinical assessment often offers a more reliable assessment of saline overload than do CVP readings (Forrester et al., 1971; Brisman, Parks and Benson, 1967) and that the role of frusemide in the management of severe water intoxication treated with hypertonic saline is worthy of further evaluation.

\section{Acknowledgment}

D.M. is indebted to Professor Oliver Wrong, University College Hospital Medical School, London, for his comments on the case.

\section{References}

Alexander, E.R., Crow, T.J. \& Hamilton, S.M. (1973) Water intoxication in relation to acute psychotic disorder. British Medical Journal, 1, 89.

Bewley, T.H. (1964) Acute water-intoxication from compulsive water-drinking. British Medical Journal, 2, 864.

Brisman, R., Parks, L.C. \& Benson, D.W. (1967) Pitfalls in the clinical use of central venous pressure. Archives of Surgery, 95, 902. 
Forrester, J.S., Diamond, G., McHugh, T.J. \& Swan, H.J.C. (1971) Filling pressures in the right and left sides of the heart in acute myocardial infarction. A reappraisal of central-venous-pressure monitoring. New England Journal of Medicine, 285, 190.

Leaf, A., Bartter, F.C., Santos, R.F. \& Wrong, O. (1953) Evidence in man that urinary electrolyte loss induced by pitressinis a function of water retention. Journal of Clinical Investigation, 32, 868.

Leaf, A., Chatillon, J.Y., Wrong, O. \& Tuttle, E.P.
(1954) The mechanism of the osmotic adjustment of the body cells. Journal of Clinical Investigation, 33, 952.

RowntreE, L.G. (1922) The water balance of the body. Physiological Reviews, 2, 116.

WynN, V. \& RoB, C.G. (1954) Water intoxication. Differential diagnosis of the hypotonic syndromes. Lancet, i, 587.

WynN, V. \& Houghton, B.J. (1957) Observations in man upon the osmotic behaviour of the body cells after trauma. Quarterly Journal of Medicine. New Series, XXVI, 375.

\title{
Contraceptive pill-induced porphyria cutanea tarda presenting with onycholysis of the finger nails
}

\author{
J. P. H. BYRne \\ M.A., M.B., M.R.C.P.(I), M.R.C.P.(U.K.)
R. P. R. DAWBER
M.B., M.R.C.P. \\ North Staffordshire Hospital Centre
}

J. M. Boss

M.B., Ch.B.

\begin{abstract}
Summary
A case of porphyria cutanea tarda induced by oral contraceptive pill therapy is reported, and its unusual presenting sign of onycholysis of the finger nails is noted. Reference is made to the rarity of nail changes in porphyria and the regression of the onycholysis in the patient following therapy is outlined.
\end{abstract}

\section{Introduction}

The porphyrias encompass a group of metabolic disorders, genetic and acquired, characterized by the excess production of porphyrins or their precursors. With the exception of acute intermittent porphyria, cutaneous manifestations, resulting from exposure to light, are prominent in these disorders and include oedema, vesicle and bulla formation, increased skin fragility, pigmentation, scarring and atrophy of the light-exposed surfaces of the body, namely the face, neck and dorsa of the hands.

Nail changes may occur in porphyria especially in the acute phase (Dean, 1975, personal communication) but the rarity of nail dystrophy is attested to by the absence of any reference to nail lesions occurring in porphyria in two major dermatological textbooks (Samman, 1972; Cairns, 1972).

Requests for reprints: Dr J. P. H. Byrne, Department of Dermatology, King's College Hospital, Denmark Hill, London SE5 9RS.
Among the nail changes that may be seen in porphyria are opaqueness, brown and bluish-grey discolorations, and loss of the lunule, but such changes are exceptionally rare in porphyria cutanea tarda compared with erythropoietic porphyria (Degos, 1970). Onycholysis, i.e. separation of the distal nail plate from its bed, has been observed in symptomatic porphyria (Tschudy, Magnus and Kalivas, 1971).

A case is reported of porphyria cutanea tarda in a young woman who had been taking an oral contraceptive agent, Norinyl-1, for 18 months, and who presented initially to her general practitioner with discoloration of her finger nails due to onycholysis.

\section{Case report}

The patient was a 21-year-old married policewoman, with no previous history of a skin disorder either in herself or her family. In January, 1974, she noted brownish discoloration of the distal parts of some of her finger nails and thumbs. She was referred to the dermatology clinic by her general practitioner where the nail discoloration was diagnosed as onycholysis. In addition, numerous vesicles, erosions and pitted scars were noted on the dorsa of the hands and face, together with hypertrichosis of the face. Associated with these signs was a feeling of soreness in these regions on exposure to light. There were no symptoms referable to the abdominal or 